\title{
Assessment of Endoscopic Gastric Atrophy according to the Kimura-Takemoto Classification and Its Potential Application in Daily Practice
}

\author{
Duc Trong Quach ${ }^{1,2}$ and Toru Hiyama ${ }^{3}$ \\ ${ }^{1}$ Department of Internal Medicine, University of Medicine and Pharmacy at Ho Chi Minh City, Vietnam, ${ }^{2}$ Department of Gastroenterology, Gia- \\ Dinh People's Hospital, Ho Chi Minh City, Vietnam, ${ }^{3}$ Health Service Center, Hiroshima University, Higashihiroshima, Hiroshima, Japan
}

The assessment of endoscopic gastric atrophy (EGA) according to the Kimura-Takemoto classification has been reported to correlate well with histological assessment. Although agreement among beginner endoscopists was less than that among experienced endoscopists, it has been shown that agreement level could markedly improve and remained stable after proper training. Several cohort studies have consistently shown that the severity of EGA at baseline is significantly associated with the presence of advanced precancerous gastric lesions and gastric cancer, as well as the development of gastric cancer in future. Patients with moderate-to-severe EGA still have high risk of gastric cancer even after successful Helicobacter pylori eradication and should be candidates for gastric cancer surveillance. The assessment of EGA, therefore, could be used as a preliminary tool to identify individuals at high risk for gastric cancer. In this paper, we review the agreement on mucosal atrophy assessment between the Kimura-Takemoto classification and histology as well as the potential application of this endoscopic classification to identify precancerous gastric lesions and gastric cancer in daily practice. Clin Endosc 2019;52:321-327

Key Words: Gastric cancer; Endoscopy; Helicobacter pylori; Surveillance; Screening

\section{INTRODUCTION}

Gastric atrophy is considered a precancerous condition, mainly caused by Helicobacter pylori infection. The condition may progress through several precancerous stages and lead to gastric cancer (GC). ${ }^{1}$ The extent as well as the severity of gastric atrophy have been shown to be associated with the risk of developing GC. ${ }^{2-5}$ Therefore, these characteristics could help to identify high-risk individuals for GC screening and surveillance.

Although the gold standard for gastric atrophy diagnosis is

Received: March 22, 2019 Revised: May 3, 2019

Accepted: May 4, 2019

Correspondence: Duc Trong Quach

Department of Internal Medicine, University of Medicine and Pharmacy at Ho Chi Minh City, 217 Hong Bang Street, District 5, Ho Chi Minh, Vietnam Tel: +84-8-3855-4269, Fax: +84-8-3950-6126, E-mail: drquachtd@ump.edu.vn ORCID: https://orcid.org/0000-0003-0141-921X

(c) This is an Open Access article distributed under the terms of the Creative Commons Attribution Non-Commercial License (http://creativecommons.org/ licenses/by-nc/3.0) which permits unrestricted non-commercial use, distribution, and reproduction in any medium, provided the original work is properly cited. histology, Kimura and Takemoto have reported that gastric atrophy changes could be endoscopically identify with high confidence since the 1960s. ${ }^{6}$ The Kimura-Takemoto endoscopic classification has been widely used in some Eastern countries. During the last 50 years, the histological definition of gastric atrophy has significantly changed to achieve better diagnostic agreement and provide useful information about GC risk. ${ }^{7-9}$ Recent advances in histological assessment of gastric atrophy have shown good agreement with the Kimura-Takemoto classification. ${ }^{10-12}$

In daily practice, there is definite benefit in comparing endoscopic and histological findings. This approach provides real-time information regarding the risk of GC, so that endoscopists can focus more on GC screening, in addition to looking for lesions that explain a patient's symptoms. This issue is extremely important as early GC detection may be very challenging. In this paper, we will review the agreement on mucosal atrophy assessment between the Kimura-Takemoto classification and histology, as well as the potential application 
of this endoscopic classification to identify precancerous gastric lesions and GC in daily practice.

\section{ENDOSCOPIC ASSESSMENT OF GASTRIC ATROPHY ACCORDING TO THE KIMURA-TAKEMOTO CLASSIFICATION}

\section{Endoscopic atrophic border}

The key to assessment of endoscopic gastric atrophy (EGA) according to the Kimura-Takemoto classification is to identify the location of the so-called endoscopic atrophic border in the stomach (Fig. 1). In 1966, Takemoto described for the first time the appearance of an "atrophic transitional zone" in patients with gastritis, subsequently known as the endoscopic atrophic border. ${ }^{6}$ This border can be recognized by discriminating mucosal differences between the 2 sides: the gastric mucosa has a lower level and is pale in color on 1 side, while it has a higher level and is homogeneously reddish on the other side. In order to clearly recognize the atrophic border, the end of the scope should be kept $5-10 \mathrm{~cm}$ from the gastric wall. ${ }^{13}$

\section{Endoscopic gastric pattern according to the Kimu- ra-Takemoto classification}

Based on location of the endoscopic atrophic border, Kimura and Takemoto proposed an endoscopic classification of gastric atrophy consisting of 2 main types: closed type (C type) and open type (O type). ${ }^{13}$ These 2 main types are further subdivided into 3 C- types (C-1, C-2 and C-3) and 3 O-types (O-1, O-2 and O-3) (Fig. 2). The closed type $\mathrm{C}-1$ is a pattern in which endoscopic atrophic findings are not visible in the corpus but only in the antrum. In type C-2 and C-3, the atrophic border starts from the greater curvature of the antrum, coming up to the anterior wall, crossing the lesser curvature, and thus making an almost symmetric enclosure. Therefore, the atrophic findings are recognized parabolically above the angulus. The differentiation between types C-2 and C-3 is based on the location of the atrophic border in relation to the middle of the stomach on the lesser curvature: the atrophic border lies below this level in type C-2 and above it in type C-3. In open types, the endoscopic atrophic area is widely spread; the atrophic border no longer lies on the lesser curvature, but instead between the lesser curvature and anterior wall in type O-1, on the anterior wall in type $\mathrm{O}-2$, and between the anterior wall and greater curvature in type O-3.

\section{Severity of gastric atrophy graded according to the Kimura-Takemoto classification and correlation with histology}

The severity of EGA is often classified into 3 grades: mild (C-1, C-2), moderate (C-3, O-1), and severe (O-2, O-3). The strength of agreement between EGA and histological atrophy according to the updated Sydney classification system was good, with a weighted kappa value of 0.51 ; this was not worse than the interobserver histological agreement between 2 pathologists. ${ }^{10}$ A recent study was conducted in patients in the UK to investigate the correlation between EGA and histological atrophy in Western patients. ${ }^{12}$ The strength of agreement on the extent of atrophy between EGA and histological atrophy showed good reproducibility, with a weighted kappa
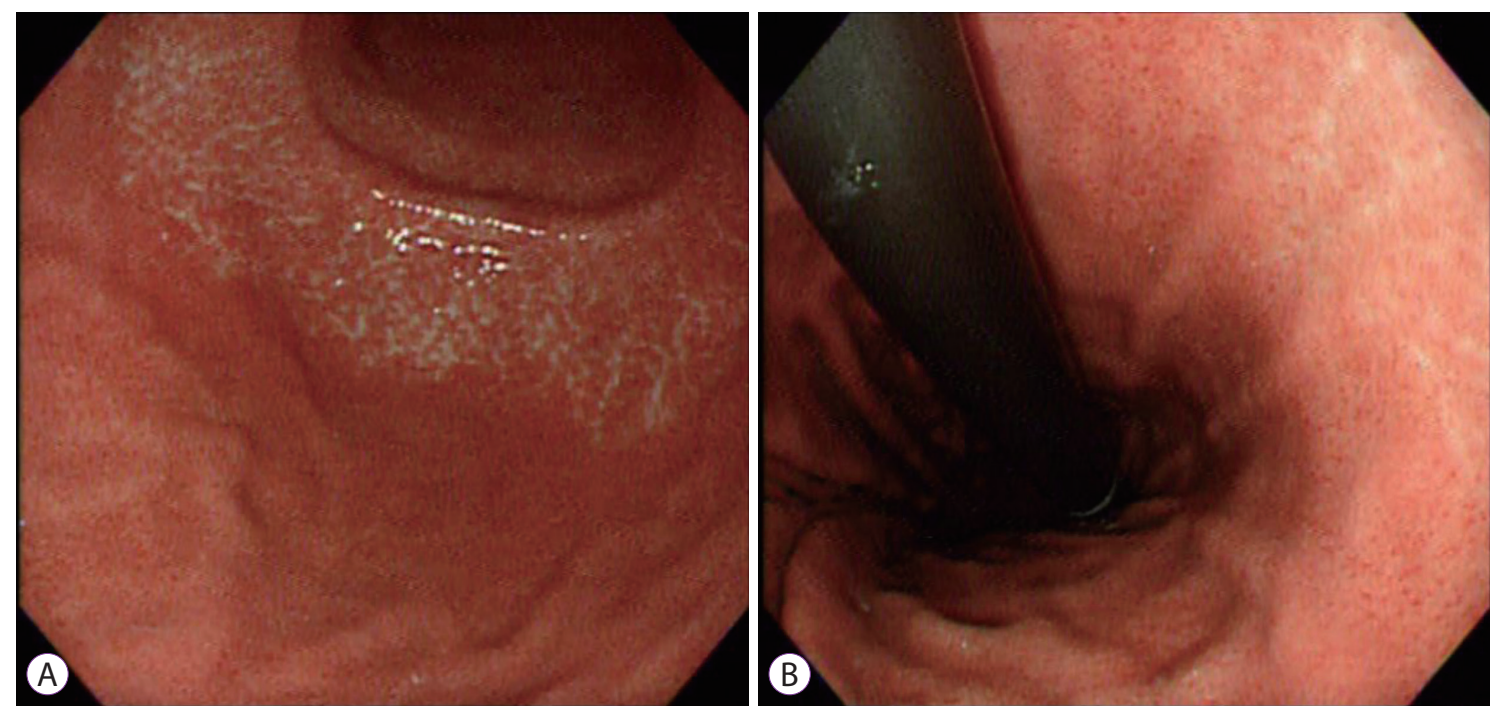

Fig. 1. Atrophic border on the greater curvature $(A)$ and lesser curvature $(B)$. The gastric mucosa shows differences in level and color between the 2 sides of the atrophic border. The endoscopic atrophic border represents both the transition from non-atrophic gastric mucosa to atrophic gastric mucosa and the transition from fundic glands to pyloric glands in a non-atrophic stomach. ${ }^{6}$ Its presence, however, does not always mean that a patient has gastric mucosal atrophy. The term "atrophic border" is not accurate and might cause some misunderstanding, but is still used in daily practice due to its historical meaning. 
value of 0.76 .

Recent advances in the histological definition and assessment of gastric atrophy have shed further light on the histological background of the Kimura-Takemoto classification. Traditionally, atrophy of the gastric mucosa was defined as the loss of glands. ${ }^{9}$ As pathologists still had considerable difficulty in reaching agreement on the nature, presence, and grading according to this definition, ${ }^{14}$ gastric atrophy was redefined as the loss of appropriate glands, comprised of 2 main morphological types: metaplastic and non-metaplastic. ${ }^{15}$ Consequently, a high level of agreement was achieved by gastrointestinal pathologists trained in different cultural contexts. ${ }^{8}$ Applying this definition of atrophy, a study was conducted to describe the topography of gastric atrophy in patients with early intestinal type GC, and found that atrophy in the corpus was present as a continuous sheet of pseudo-pyloric metaplasia and formed an advancing atrophic front. ${ }^{16}$ The presence of a histologically atrophic front is, therefore, similar to the spread of antral mucosa towards the corpus and is faster in the lesser curvature; this pattern is identical to that of atrophic extension endoscopically described by Kimura and Takemoto.

The Operative Link on Gastritis Assessment (OLGA) staging system was recently proposed to provide information regarding GC risk. ${ }^{15}$ Observational studies in populations with different risk levels for GC have shown that precancerous and neoplastic gastric lesions clustered in high OLGA stages (i.e., stage III and IV). ${ }^{2,311}$ Recently, large prospective studies have confirmed that OLGA staging reliably predicts the risk for development of GC., ${ }^{4,5}$ Our previous study showed that the severity of EGA was significantly correlated with that of OLGA

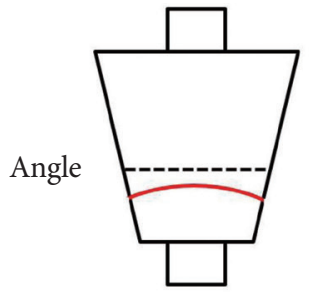

C-1

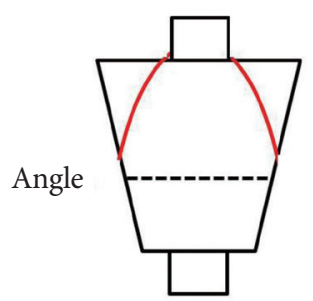

O-1

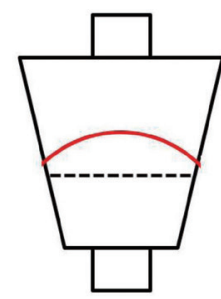

C-2

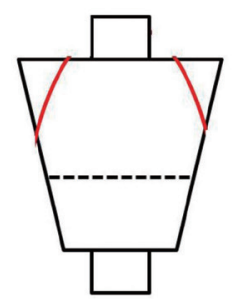

$\mathrm{O}-2$

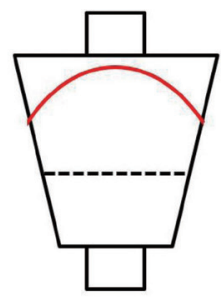

C-3

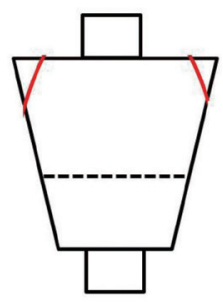

O-3
Fig. 2. Extension of the atrophic border (red line) and patterns of endoscopic gastric atrophy as classified by Kimura and Takemoto. ${ }^{13}$ stage in Vietnamese patients with dyspepsia. ${ }^{11}$ All patients with high OLGA stages had moderate-to-severe EGA. Using moderate-to-severe EGA as the diagnostic criterion for high OLGA stage, the sensitivity, specificity, positive predictive value, and negative predictive value were $100 \%, 57.7 \%, 10.3 \%$, and $100 \%$, respectively.

\section{Interobserver and intraobserver agreement for gas- tric mucosal atrophy assessment according to the Kimura-Takemoto classification}

Good to excellent intraobserver agreement and moderate interobserver agreement among endoscopists with $\geq 7$ years of experience have been reported. However, the intraobserver and interobserver agreement among beginner endoscopists ( $\leq 3$ years of experience) was lower and ranged wider than that in experienced endoscopists. ${ }^{17}$ Recently, a prospective study was conducted in Korea to evaluate the effect of training on interobserver agreement in diagnosis and grading of EGA according to the level of an endoscopist's experience. ${ }^{18}$ Six less-experienced ( $\leq 10$ years of experience) and 6 experienced endoscopists ( $\geq 10$ years) participated in the study. The training session consisted of 4 interventions with 2 -week intervals, and 2 follow-up assessments without feedback. This study showed that interobserver agreement for diagnosis and grading of EGA improved after training and remained stable after intervention, irrespective of experience level.

\section{Progression of gastric atrophy assessed with the Kimura-Takemoto classification}

Few studies have investigated progression of gastric atrophy using the Kimura-Takemoto classification before and after eradication.

A 10-year, prospective follow-up study was performed in Japan to assess the natural progression of EGA. Annual upper gastrointestinal endoscopy found that all patients without $H$. pylori infection had no endoscopic or histological change. In contrast, $43 \%$ of patients with $H$. pylori infection exhibited a cephalad shift of the endoscopic atrophic border. Progression of histological atrophy and intestinal metaplasia (IM) was observed in $46 \%$ and $49 \%$ of these patients, respectively. ${ }^{19}$

Another study in Japan was conducted to assess the relationship of EGA with histological atrophy and IM before and after $H$. pylori eradication. ${ }^{20}$ Endoscopic findings were reported at approximately 78 months after eradication. Compared with the grades assigned before eradication, an improvement in endoscopic grade was observed in $40.1 \%$ of patients, while no change or exacerbation of atrophy was observed in $33.9 \%$ and $25.2 \%$ of patients following successful eradication, respectively. There was a significant correlation of EGA with histological atrophy and IM, but not with antral atrophy after 
eradication. The histological atrophy scores showed significant improvement after eradication, while IM showed no significant change. The findings of this study were very important as they implied that the risk of GC development could not be eliminated if baseline IM was present, even in patients with improved EGA after $H$. pylori eradication.

\section{CLINICAL APPLICATION IN DAILY PRACTICE}

\section{Moderate-to-severe EGA as an endoscopic indicator for the presence of gastric cancer}

Although chromoendoscopy and image-enhanced endos- copy can improve the detection of subtle gastric lesions, ${ }^{21}$ endoscopic examination generally starts with white-light endoscopy. This is a very important step because pre-endoscopic screening is sometimes insufficient and the stomach may need further cleaning. Moderate-to-severe EGA observed during the procedure indicates that patients are at high-risk of GC and endoscopic examination should be performed very carefully. The relationship between GC lesions and an atrophic border helps endoscopists to focus on the locations where GC is more likely to occur. At least 2 studies have reported this interesting finding. One study reported that about $85 \%$ of GCs (including 93\% of intestinal type) occurred on the distal side of the atrophic border. ${ }^{22}$ Early diffuse-type GCs arose closer to the atrophic border than intestinal-type GCs and were more
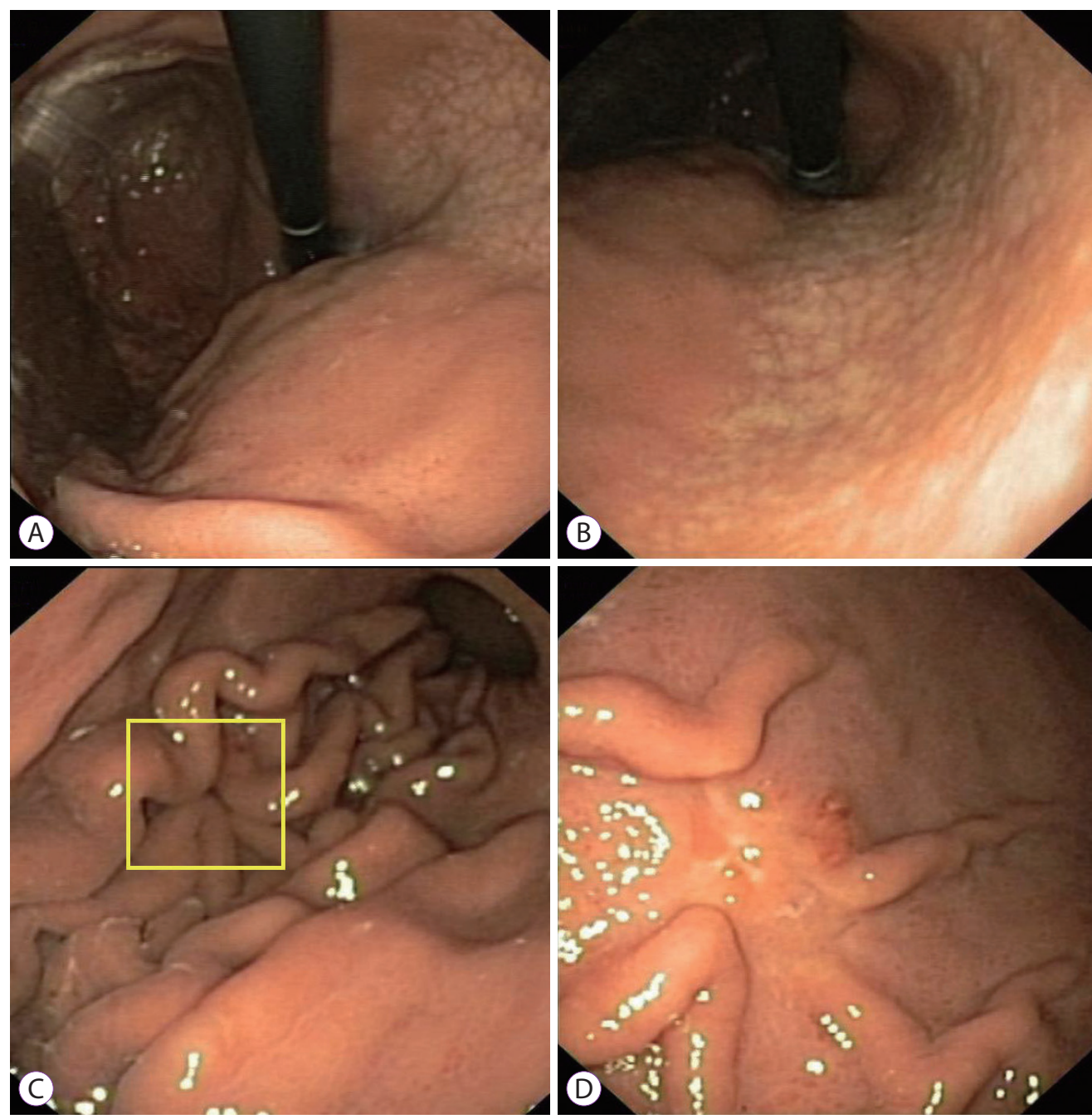

Fig. 3. A 24-year-old Vietnamese female underwent upper gastrointestinal endoscopy for epigastric pain. The patient had no alarming features. (A, B) White-light endoscopy clearly demonstrated moderate endoscopic gastric atrophy (type 0-1), even with an older-generation gastroscope (Olympus EXERA-GIF 160 Video Gastroscope; Olympus Co., Tokyo, Japan), which prompted the endoscopist to search carefully for gastric cancer. (C) An easily-missed subtle change (yellow box) could be identified on the greater curvature of the corpus. (D) The gastroscope was advanced closer to the suspicious area and more air was insufflated. A small 0-Ilc lesion hidden beneath gastric mucosal folds was identified. This lesion was diagnosed as undifferentiated adenocarcinoma on pathology. 
likely to be located proximal to the border. The mean distance between cancer and the atrophic border in intestinal- and diffuse-type GCs was 2.40 and $1.45 \mathrm{~cm}$, respectively. Another study found that $98.4 \%$ of early GCs after $H$. pylori eradica-

Table 1. The Severity of Endoscopic Gastric Atrophy at Baseline as a Risk Factor of Gastric Cancer Development

\begin{tabular}{|c|c|c|c|c|c|c|c|}
\hline Study & Type of study & $\begin{array}{c}\text { Number of } \\
\text { patients }\end{array}$ & $\begin{array}{l}\text { H. pylori } \\
\text { status }\end{array}$ & $\begin{array}{l}\text { Follow-up } \\
\text { period (yr) }\end{array}$ & $\begin{array}{c}\text { Number of } \\
\text { cancer }\end{array}$ & $\begin{array}{l}\text { EGA severity as } \\
\text { risk factor }\end{array}$ & Other risk factors \\
\hline Uemura et al. ${ }^{38}$ & $\begin{array}{l}\text { Prospective } \\
\text { cohort study }\end{array}$ & 1,526 & $\begin{array}{l}\text { Before eradi- } \\
\text { cation }\end{array}$ & 7.8 & 36 & Severe $(\mathrm{O}-2, \mathrm{O}-3)$ & $\begin{array}{l}\text { Corpus-predomi- } \\
\text { nant gastritis } \\
\text { Intestinal metaplasia }\end{array}$ \\
\hline Kaji et al. ${ }^{29}$ & $\begin{array}{l}\text { Retrospective } \\
\text { cohort study }\end{array}$ & 12,941 & N/A & 3.6 & 63 & $\begin{array}{c}\text { Open type }>\text { C-2, } \\
\text { C-3 > C-1, C-0 }\end{array}$ & $\begin{array}{l}\text { Age } \geq 62 \\
\text { Presence of ulcer } \\
\text { Uric acid level }\end{array}$ \\
\hline Hosokawa et al. ${ }^{39}$ & $\begin{array}{l}\text { Retrospective } \\
\text { cohort study }\end{array}$ & 3,672 & $\mathrm{~N} / \mathrm{A}$ & 1.9 & 32 & Severe $(\mathrm{O} 2, \mathrm{O} 3)$ & Age (60-69) \\
\hline Masuyama et al. ${ }^{26}$ & Cross-sectional & 27,777 & $\mathrm{~N} / \mathrm{A}$ & 13 & 407 & $\begin{array}{l}\text { C-2 or more } \\
\text { severe }\end{array}$ & \\
\hline Sekikawa et al. ${ }^{35}$ & $\begin{array}{l}\text { Retrospective } \\
\text { cohort study }\end{array}$ & 1,823 & $\mathrm{~N} / \mathrm{A}$ & 8.0 & 29 & Open type & Gastric xanthelasma \\
\hline Sugimoto et al. ${ }^{36}$ & Cross-sectional & 1,200 & N/A & 4.6 & 79 & Severe $(\mathrm{O}-2, \mathrm{O}-3)$ & Intestinal metaplasia \\
\hline Take et al. ${ }^{30}$ & $\begin{array}{l}\text { Prospective } \\
\text { cohort study }\end{array}$ & 1,674 & $\begin{array}{l}\text { Post successful } \\
\text { eradication }\end{array}$ & 14.1 & 28 & Open type, C-3 & \\
\hline Toyoshima et al. ${ }^{31}$ & $\begin{array}{l}\text { Retrospective } \\
\text { cohort study }\end{array}$ & 1,232 & $\begin{array}{l}\text { Post successful } \\
\text { eradication }\end{array}$ & 2.5 & 15 & $\begin{array}{l}\text { Open type }>\text { C-2, } \\
\text { C-3 }\end{array}$ & - \\
\hline Shichijo et al. ${ }^{37}$ & $\begin{array}{l}\text { Retrospective } \\
\text { cohort study }\end{array}$ & 573 & $\begin{array}{l}\text { Post successful } \\
\text { eradication }\end{array}$ & 6.2 & 21 & $\begin{array}{c}\text { Open type }>\text { C-2, } \\
\text { C-3 }>\text { C-1, C-0 }\end{array}$ & Intestinal metaplasia \\
\hline Sakitani et al. ${ }^{33}$ & $\begin{array}{l}\text { Retrospective } \\
\text { cohort study }\end{array}$ & 965 & $\begin{array}{l}\text { Post successful } \\
\text { eradication }\end{array}$ & 4.5 & 21 & $\mathrm{O}-2, \mathrm{O}-3$ & - \\
\hline Kodama et al. ${ }^{34}$ & $\begin{array}{l}\text { Retrospective } \\
\text { cohort study }\end{array}$ & 2,355 & $\begin{array}{l}\text { Post successful } \\
\text { eradication }\end{array}$ & 2.4 & 33 & $\begin{array}{l}\text { C-3 or more } \\
\text { severe }\end{array}$ & Intestinal metaplasia \\
\hline
\end{tabular}

EGA, endoscopic gastric atrophy; N/A, not applicable.

Table 2. The Severity of Endoscopic Gastric Atrophy at Baseline as a Risk Factor of Synchronous and Metachronous Gastric Cancer

\begin{tabular}{|c|c|c|c|c|c|c|c|}
\hline Study & Type of study & $\begin{array}{l}\text { Number of } \\
\text { patients }\end{array}$ & $\begin{array}{c}\text { Patients' charac- } \\
\text { teristics }\end{array}$ & $\begin{array}{l}\text { Duration } \\
\text { of study } \\
(y r)\end{array}$ & $\begin{array}{l}\text { Type and number } \\
\text { of patients with } \\
\text { gastric neoplasm }\end{array}$ & $\begin{array}{c}\text { EGA severity } \\
\text { as a high-risk } \\
\text { factor }\end{array}$ & $\begin{array}{l}\text { Other high-risk } \\
\text { factors }\end{array}$ \\
\hline Mori et al. ${ }^{42}$ & $\begin{array}{l}\text { Retrospective } \\
\text { cohort study }\end{array}$ & 594 & $\begin{array}{l}\text { After EMR/ESD } \\
\text { Successful } H . \text { pylori } \\
\text { eradication }\end{array}$ & 4.5 & 79 (MGC) & $\begin{array}{c}\text { Severe } \\
(\mathrm{O}-2 / \mathrm{O}-3)\end{array}$ & $\begin{array}{l}\text { Male } \\
\text { Number of GC } \\
\text { before successful } H . \\
\text { pylori eradication }\end{array}$ \\
\hline $\begin{array}{l}\text { Masuyama et } \\
\text { al. }^{26}\end{array}$ & Cross-sectional & 272 & N/A & 13.0 & $\begin{array}{l}30 \text { (SGC) } \\
20 \text { (MGC) }\end{array}$ & Open type & - \\
\hline Nam et al. ${ }^{43}$ & $\begin{array}{l}\text { Retrospective } \\
\text { cohort study }\end{array}$ & 488 & $\begin{array}{l}\text { After ESD / Sur- } \\
\text { gery }\end{array}$ & 3.1 & $\begin{array}{l}18 \text { (MGC) } \\
7(\mathrm{MHD}) \\
52(\mathrm{MLD})\end{array}$ & $\begin{array}{c}\text { C-3 or } \\
\text { more severe }\end{array}$ & $\begin{array}{l}\text { Age } \geq 65 \\
\text { elevated morphology } \\
\text { of primary lesions }\end{array}$ \\
\hline
\end{tabular}

Synchronous gastric cancer (SGC), synchronous high-grade dysplasia and synchronous low-grade dysplasia were defined as gastric epithelial neoplastic lesions that have already been detected before the initial endoscopic submucosal dissection (ESD) or found endoscopically and confirmed pathologically with endoscopic forceps biopsy within 1 year of ESD. Metachronous gastric cancer (MGC) was defined as a new GC detected at least 1 year after successful $H$. pylori eradication and located in an area other than the site of the previous endoscopic resection.

EGA, endoscopic gastric atrophy; EMR, endoscopic mucosal resection; MHD, metachronous high-grade dysplasia; MLD, metachronous low-grade dysplasia; N/A, no applicable. 
tion were located within the endoscopically atrophic mucosa or along the atrophic border. ${ }^{23}$ Synchronous GC is also a concern for endoscopists as its incidence is about $6.8 \%$ to $8.1 \%$ after endoscopic resection of early GCs. ${ }^{24,25}$ It is important to identify patients who are more likely to have synchronous GC at the time the primary GC is detected. A recent study on patients with synchronous multiple GCs found that $96.7 \%$ had baseline open-type (i.e., type O-1, O-2, and O-3) gastric atrophy. ${ }^{26}$ As EGA can be assessed using white-light endoscopy, this finding is widely applicable, especially in areas with limited resources (Fig. 3). A recent global consensus on gastritis recommends that assessment for EGA can be used initially in areas with proven expertise in endoscopic scoring, although histological confirmation is still recommended. ${ }^{27}$

\section{Moderate-to-severe EGA as an indicator for high risk of GC development}

As successful eradication of $H$. pylori could not eliminate the risk of $\mathrm{GC}^{28-34}$ it is important to identify high-risk individuals who still need surveillance after eradication. Several studies have consistently confirmed that the severity of EGA at baseline is associated with not only the current presence of GC but also the risk for GC development (Table 1). ${ }^{26,29-31,33-39}$

The presence of moderate-to-severe EGA at baseline consistently indicates a high risk of GC development. However, recent cohort studies with long-term follow-up reported that GCs may still occur in patients with none/mild EGA, ${ }^{31,37}$ but with a much lower proportion compared to patients with moderate-to-severe EGA. GCs in these patients commonly occurred very late, usually after $4-5$ years, and up to more than 10 years after eradication. ${ }^{31,40}$ Considering the different carcinogenesis pathways in intestinal-type GC and diffuse-type GC, one would presume that EGA severity is a better indicator of the former than the latter. Indeed, a longterm cohort study reported that the frequency of severe atrophy was significantly higher in patients with intestinal-type GC than in those with diffuse-type GC who did not undergo H. pylori eradication. ${ }^{38}$ However, 10 of 13 patients with diffuse-type GC in this study had baseline moderate-to-severe EGA. Furthermore, several cohort studies in patients who had undergone $H$. pylori eradication consistently found very few GCs, including diffuse-type GCs, in patients with baseline none/mild EGA. ${ }^{26,31,37}$ Therefore, moderate-to-severe EGA is a good indicator for the development of intestinal-type GC as well as diffuse-type GC.

After endoscopic resection or surgery for GC, patients are still at high risk and should undergo surveillance for metachronous lesions. H. pylori eradication is helpful to reduce the incidence of metachronous GC in these patients. ${ }^{41}$ However, eradication therapy can make the detection of metachronous
GC very challenging, as post-eradication GC lesions often have a depressed-type and gastritis-like appearance. ${ }^{32}$ Some studies have reported that moderate-to-severe EGA is a risk factor for metachronous GC (Table 2) ${ }^{26,42,43}$ Therefore, endoscopists should also carefully search for subtle suspicious lesions in patients with this endoscopic finding.

Most published studies on a surveillance strategy for patients with moderate-to-severe EGA offered patients an annual or biannual endoscopic screening interval. ${ }^{31,37,39}$ However, as we previously reported that the distribution of high-stage OLGA gastritis was not homogeneous among patients with the endoscopic finding of extensive and incomplete IM, ${ }^{44}$ histological examination may be useful to further stratify the risk levels of GC for determination of more appropriate surveillance intervals. This is an important and interesting question for future research.

\section{CONCLUSIONS}

In summary, grading EGA according to the Kimura-Takemoto classification has been reported to correlate well with histological assessment according to the updated Sydney system and the OLGA system. Several cohort studies have consistently shown that moderate-to-severe EGA at baseline is significantly associated with the presence of advanced precancerous gastric lesions and GC, as well as the development of GC. Although agreement among beginner endoscopists was lower than that among experienced endoscopists, it has been shown that agreement could markedly improve and remain stable after training. The Kimura-Takemoto classification, therefore, could be widely used in daily practice as a preliminary tool to identify individuals at high risk for GC.

Conflicts of Interest

The authors have no financial conflicts of interest.

Author contributions

Conceptualization: Duc Trong Quach

Writing-original draft: DTQ

Writing-review\&editing: DTQ, Toru Hiyama

\section{REFERENCES}

1. Correa P. Helicobacter pylori and gastric carcinogenesis. Am J Surg Pathol 1995;19 Suppl 1:S37-S43.

2. Rugge M, Meggio A, Pennelli G, et al. Gastritis staging in clinical practice: the OLGA staging system. Gut 2007;56:631-636.

3. Satoh K, Osawa H, Yoshizawa M, et al. Assessment of atrophic gastritis using the OLGA system. Helicobacter 2008;13:225-229.

4. Rugge M, Genta RM, Fassan M, et al. OLGA gastritis staging for the 
prediction of gastric cancer risk: a long-term follow-up study of 7436 patients. Am J Gastroenterol 2018;113:1621-1628.

5. Rugge M, Meggio A, Pravadelli C, et al. Gastritis staging in the endoscopic follow-up for the secondary prevention of gastric cancer: a 5-year prospective study of 1755 patients. Gut 2019;68:11-17.

6. Kimura K, Takemoto T. An endoscopic recognition of the atrophic border and its significance in chronic gastritis. Endoscopy 1969;1:87-97.

7. Dixon MF, Genta RM, Yardley JH, Correa P. Classification and grading of gastritis. The updated Sydney System. International Workshop on the Histopathology of Gastritis, Houston 1994. Am J Surg Pathol 1996;20:1161-1181.

8. Rugge M, Correa P, Dixon MF, et al. Gastric mucosal atrophy: interobserver consistency using new criteria for classification and grading. Aliment Pharmacol Ther 2002;16:1249-1259.

9. Correa P. Chronic gastritis: a clinico-pathological classification. Am J Gastroenterol 1988;83:504-509.

10. Liu Y, Uemura N, Xiao SD, Tytgat GN, Kate FJ. Agreement between endoscopic and histological gastric atrophy scores. J Gastroenterol 2005;40:123-127.

11. Quach DT, Le HM, Nguyen OT, Nguyen TS, Uemura N. The severity of endoscopic gastric atrophy could help to predict operative link on gastritis assessment gastritis stage. J Gastroenterol Hepatol 2011;26:281-285.

12. Kono S, Gotoda T, Yoshida S, et al. Can endoscopic atrophy predict histological atrophy? Historical study in United Kingdom and Japan. World J Gastroenterol 2015;21:13113-13123.

13. Kimura K, Satoh K, Ido K, Taniguchi Y, Takimoto T, Takemoto T. Gastritis in the Japanese stomach. Scand J Gastroenterol Suppl 1996;214:1720; discussion 21-13.

14. Andrew A, Wyatt JI, Dixon MF. Observer variation in the assessment of chronic gastritis according to the Sydney system. Histopathology 1994;25:317-322.

15. Rugge M, Genta RM. Staging gastritis: an international proposal. Gastroenterology 2005;129:1807-1808.

16. El-Zimaity HM, Ota H, Graham DY, Akamatsu T, Katsuyama T. Patterns of gastric atrophy in intestinal type gastric carcinoma. Cancer 2002;94:1428-1436

17. Miwata T, Quach DT, Hiyama T, et al. Interobserver and intraobserver agreement for gastric mucosa atrophy. BMC Gastroenterol 2015;15:95.

18. Jin EH, Chung SJ, Lim JH, et al. Training effect on the inter-observer agreement in endoscopic diagnosis and grading of atrophic gastritis according to level of endoscopic experience. J Korean Med Sci 2018;33:e117.

19. Sakaki N, Kozawa H, Egawa N, Tu Y, Sanaka M. Ten-year prospective follow-up study on the relationship between Helicobacter pylori infection and progression of atrophic gastritis, particularly assessed by endoscopic findings. Aliment Pharmacol Ther 2002;16 Suppl 2:198-203.

20. Kodama M, Okimoto T, Ogawa R, Mizukami K, Murakami K. Endoscopic atrophic classification before and after $\mathrm{H}$. pylori eradication is closely associated with histological atrophy and intestinal metaplasia. Endosc Int Open 2015;3:E311-E317.

21. Chiu PWY, Uedo N, Singh R, et al. An Asian consensus on standards of diagnostic upper endoscopy for neoplasia. Gut 2019;68:186-197.

22. Yoshimura T, Shimoyama T, Fukuda S, Tanaka M, Axon AT, Munakata A. Most gastric cancer occurs on the distal side of the endoscopic atrophic border. Scand J Gastroenterol 1999;34:1077-1081.

23. Tahara T, Shibata T, Horiguchi N, et al. A possible link between gastric mucosal atrophy and gastric cancer after Helicobacter pylori eradication. PLoS One 2016;11:e0163700.

24. Nishida T, Tsujii M, Kato M, et al. Endoscopic surveillance strategy after endoscopic resection for early gastric cancer. World J Gastrointest Pathophysiol 2014;5:100-106.
25. Lee HJ, Lee YJ, Lee JY, et al. Characteristics of synchronous and metachronous multiple gastric tumors after endoscopic submucosal dissection of early gastric neoplasm. Clin Endosc 2018;51:266-273.

26. Masuyama H, Yoshitake N, Sasai T, et al. Relationship between the degree of endoscopic atrophy of the gastric mucosa and carcinogenic risk. Digestion 2015;91:30-36.

27. Sugano K, Tack J, Kuipers EJ, et al. Kyoto global consensus report on Helicobacter pylori gastritis. Gut 2015;64:1353-1367.

28. Chen HN, Wang Z, Li X, Zhou ZG. Helicobacter pylori eradication cannot reduce the risk of gastric cancer in patients with intestinal metaplasia and dysplasia: evidence from a meta-analysis. Gastric Cancer 2016;19:166-175.

29. Kaji K, Hashiba A, Uotani C, et al. Grading of atrophic gastritis is useful for risk stratification in endoscopic screening for gastric cancer. Am J Gastroenterol 2019;114:71-79.

30. Take S, Mizuno M, Ishiki K, et al. The long-term risk of gastric cancer after the successful eradication of Helicobacter pylori. J Gastroenterol 2011;46:318-324

31. Toyoshima O, Yamaji Y, Yoshida S, et al. Endoscopic gastric atrophy is strongly associated with gastric cancer development after Helicobacter pylori eradication. Surg Endosc 2017;31:2140-2148.

32. Shichijo S, Hirata Y. Characteristics and predictors of gastric cancer after Helicobacter pylori eradication. World J Gastroenterol 2018;24:21632172.

33. Sakitani K, Hirata Y, Suzuki N, et al. Gastric cancer diagnosed after Helicobacter pylori eradication in diabetes mellitus patients. BMC Gastroenterol 2015;15:143.

34. Kodama M, Murakami K, Okimoto T, et al. Histological characteristics of gastric mucosa prior to Helicobacter pylori eradication may predict gastric cancer. Scand J Gastroenterol 2013;48:1249-1256.

35. Sekikawa A, Fukui H, Sada R, et al. Gastric atrophy and xanthelasma are markers for predicting the development of early gastric cancer. J Gastroenterol 2016;51:35-42.

36. Sugimoto M, Ban H, Ichikawa H, et al. Efficacy of the Kyoto classification of gastritis in identifying patients at high risk for gastric cancer. Intern Med 2017;56:579-586.

37. Shichijo S, Hirata Y, Niikura R, et al. Histologic intestinal metaplasia and endoscopic atrophy are predictors of gastric cancer development after Helicobacter pylori eradication. Gastrointest Endosc 2016;84:618-624.

38. Uemura N, Okamoto S, Yamamoto S, et al. Helicobacter pylori infection and the development of gastric cancer. N Engl J Med 2001;345:784-789.

39. Hosokawa O, Watanabe K, Hatorri M, Douden K, Hayashi H, Kaizaki $\mathrm{Y}$. Detection of gastric cancer by repeat endoscopy within a short time after negative examination. Endoscopy 2001;33:301-305.

40. Majima A, Handa O, Naito Y, et al. Early-stage gastric cancer can be found in improved atrophic mucosa over time from successful Helicobacter pylori eradication. Digestion 2017;95:194-200.

41. Fukase K, Kato M, Kikuchi S, et al. Effect of eradication of Helicobacter pylori on incidence of metachronous gastric carcinoma after endoscopic resection of early gastric cancer: an open-label, randomised controlled trial. Lancet 2008;372:392-397.

42. Mori G, Nakajima T, Asada K, et al. Incidence of and risk factors for metachronous gastric cancer after endoscopic resection and successful Helicobacter pylori eradication: results of a large-scale, multicenter cohort study in Japan. Gastric Cancer 2016;19:911-918.

43. Nam HS, Kim HW, Choi CW, et al. Characteristics of overlooked synchronous gastric epithelial neoplasia after endoscopic submucosal dissection. Medicine (Baltimore) 2018;97:e12536.

44. Quach DT, Le HM, Hiyama T, Nguyen OT, Nguyen TS, Uemura N. Relationship between endoscopic and histologic gastric atrophy and intestinal metaplasia. Helicobacter 2013;18:151-157. 